\title{
NAS PÁGINAS DOS JORNAIS: O CARÁTER DIPLOMÁTICO ATRIBUÍDO À TRADUÇÃO LITERÁRIA EM MEADOS DO SÉCULO XX $\mathbf{X}^{1}$.
}

Marly D'Amaro Blasques Tooge

RESUMO: O período da Segunda Guerra Mundial, quando o mercado editorial europeu se fechou para as Américas, surgindo a necessidade de alianças politicas estratégicas no continente americano, foi marcado por um aumento do número de traduções de obras brasileiras levadas para os Estados Unidos. Através da política de "Boa Vizinhança" do governo Roosevelt, foi criado o Gabinete do Coordenador de Assuntos Interamericanos (OCIAA), chefiado por Nelson Rockefeller, onde passou a funcionar um programa de intercâmbio cultural entre os Estados Unidos e o Brasil. Desse programa fazia parte o incentivo à literatura traduzida, vista como fonte de conhecimento mútuo. Criou-se, então, um padrão de comportamento que perdurou por décadas. Érico Veríssimo, Gilberto Freyre, Alfred e Blanche Knopf, Samuel Putnam e Harriet de Onís foram atores importantes nesse processo. E apesar de seu posicionamento de esquerda, até mesmo o escritor Jorge Amado se tornaria, na década de 1960, um bestseller americano, através dessa vertente "diplomática" da tradução. Os fatos acima descritos foram evidenciados em jornais e revistas da época, cuja cobertura é também apresentada neste artigo.

1 Uma versão preliminar deste artigo foi apresentada no Congresso Internacional da ABRALIC, em junho de 2008.

* Mestranda do Programa de Estudos Linguísticos e Literários em Inglês do Departamento de Letras Modernas da Faculdade de Filosofia, Letras e Ciências Humanas da USP. 
UNITERMOS: tradução; literatura; cultura; diplomacia.

ABSTRACT: During World War II, the difficulty in bringing European translated literuature to the United States and the need to foster political and staregic alliances between the Americas led to an increase in the number of Brazilian books tanslated into English and published in the US. The Office of Inter-American Affairs, headed by Nelson Rockefeller, seeking to disseminate knowledge of U.S. culture in Latin America and cultivate cultural goodwill, sponsored a cultural exchange program, which included grants to Latin American translated literature, which was seen as a means to understand "the other". Rockefeller's program established a patter of behavior among translation agents that lasted for decades. Érico Veríssimo, Gilberto Freyre, Alfred and Blanche Knopf, Samuel Putnam and Harriet de Onís were important actors in this process. Even Jorge Amado, depite his leftist background, became an American bestseller, as a consequence of this "diplomatic" translation program. The aforementioned facts, reported in the American newspapers and magazines, are also presented in this article..

KEYWORDS: translation; literature; culture; diplomacy.

\section{Introdução}

Entre a Segunda Guerra Mundial e a Guerra Fria, a literatura estrangeira traduzida foi vista pelo governo dos Estados Unidos e por intelectuais brasileiros e americanos como ferramenta para conhecer a cultura do "outro", assim como instrumento para fortalecer alianças políticas. Nesse período os jornais norte-americanos, com destaque para o The New York Times, funcionaram tanto como fontes de narrativas sobre os acontecimentos politicos internacionais, quanto como formuladores de imagens das nações estrangeiras. Eles também atuaram como veículos de opinião de agentes literários. Jornal e romance, as duas formas de comunicação escrita tidas por Benedict Anderson, em Comunidades Imaginadas (1983:25), como responsáveis pela formação da ima-

TradTerm, 15, 2009, p. 59-78 
gem da nação moderna, criam as bases para o fenômeno demonstrado a seguir. Neste artigo, veremos, pois, a forma como traduções de obras literárias brasileiras foram introduzidas nos Estados Unidos a partir dos projetos governamentais e particulares vinculados à filosofia da "Boa Vizinhança".

\section{Panorama politico nas Américas em meados do Século XX}

Herbert Hoover, presidente dos Estados Unidos entre 1929 e 1933, foi quem primeiro utilizou a expressão good neighbor(Tota, 2000:28) ao fazer uma viagem diplomática à América Latina, logo no início de seu mandato. Foi a semente do que se tornaria, mais tarde, a "marca registrada" do Governo de Franklin Delano Roosevelt, e sua política de "Boa Vizinhança", aplicada a partir de 1933. A articulação desses governos, contrariando a filosofia do Big Stick ${ }^{2}$ de seus predecessores, não se baseava mais na intervenção armada, mas na defesa através da cooperação continental (Idem, ibidem:43). Para isso, foi criado o Gabinete do Coordenador de Assuntos Interamericanos (Office of the Coordinator of Inter-American Affairs - OCIAA) encabeçado pelo empresário Nelson Rockefeller e filiado ao Departamento de Estado. Uma das divisões do OCIAA era a de Relações Culturais, à qual se atribuiu grande importância no processo da formação de uma política "Hemisférica" (Idem, ibidem:51).

O rádio e o cinema foram os dois grandes alvos da politica de intercâmbio cultural do OCIAA. Mas a literatura não ficou de fora desse projeto. A princípio, o Departamento de Estado Americano começou a incentivar as universidades e as editoras para a tradução de obras literárias da América Latina. Mas o que seria uma

2 O termo "Big Stick" (grande porrete) referia-se à política diplomática empregada por Theodore Roosevelt, como corolário da Doutrina Monroe, segundo a qual os Estados Unidos atuavam como polícia internacional no hemisfério ocidental, incluindo, em sua politica, as intervenções internacionais.

TradTerm, 15, 2009, p. 59-78 
iniciativa modesta, com baixos custos para uma atividade de alto risco financeiro ${ }^{3}$, acabou por se intensificar com a criação do OCIAA.

\section{A Ação dos intelectuais brasileiros nos Estados Unidos}

A ideia de panamericanismo gerou o patrocínio de intercâmbios de artistas, escritores, músicos e cineastas. Foi nesse contexto que se formaram ícones e personagens representativos da América Latina e do Brasil, como Carmem Miranda e o Zé Carioca. Nomes como Heitor Villa Lobos, Cândido Portinari, Ary Barroso e Elsie Houston, entre outros, tiveram destaque na New York World's Fair (Tota, 2000:97-101).

Já o maior representante de nossa literatura no início da década de 1940 foi o escritor Érico Veríssimo. O autor gaúcho foi convidado pelo Departamento de Estado Americano a visitar os Estados Unidos como porta-voz da cultura brasileira, sendo apresentado como consultor de uma importante editora do sul do Brasil, a Editora Globo. Na verdade, Veríssimo era o tradutor de várias obras americanas publicadas no Brasil. Era também originário do Rio Grande do Sul, fato que também não pode ser negligenciado, já que toda a região sul brasileira, onde existiam colônias alemãs e italianas, era temida pelo possivel apoio às "ideias nazistas de uma grande Fatherland germânica, que se estenderia por toda a América Latina" (Tota, 2000:88). Mas Veríssimo, ao contrário, era um "bom informante", um conhecido escritor brasileiro, que representava o apoio aos Estados Unidos e a oposição tanto ao fascismo quanto ao comunismo. Segundo a imprensa da época, Veríssimo apresentava a seguinte proposta:

3 O The New York Times de 30 de dezembro de 1939 trazia uma nota anunciando que o Departamento de Estado passava a incentivar, através de um projeto na Universidade de Cleveland, a publicação de traduções de baixo custo, por meio de trabalho voluntário e renúncia de direitos autorais, para trazer o produto da escrita dos países latino-americanos ao público norte-americano. Era a fórmula para expandir as relações culturais e o entendimento mútuo. No entanto, para ser lucrativa uma publicação precisaria implicar uma venda acima de 2000 exemplares.

TradTerm, 15, 2009, p. 59-78 
Sua ideia é a de que as relações interamericanas podem ser forjadas por uma troca mútua de conhecimento sobre a literatura das duas Américas - não literatura no senso "literário", mas livros a serem lidos por diversão (...) O que o Sr. Veríssimo tem em mente é completamente diferente do tipo lisonjeiro de intercâmbio literário. Sua ideia é a de que a compreensão do bom e do ruim é necessária e que, quando tais relações têm cara de propaganda, elas falham. A tendência na literatura brasileira já é em direção aos Estados Unidos, ele destaca. ${ }^{4}$ (Los Angeles Times, 18 de abril de 1941)

A posição de Veríssimo, semelhante à de alguns artistas que foram aos Estados Unidos, transparece em suas declarações, tanto nos jornais norte-americanos, quanto nas palestras e cursos que proferiu nos Estados Unidos. Ela seguia a linha de pensamento de intelectuais como Waldo Frank ${ }^{6}$, que acreditavam que o Brasil também tinha muito a ensinar ao país ianque. Se, por um lado, eles tinham a grande indústria e o progresso tecnológico, produzindo um consumismo exacerbado, numa democracia comprometida pela conhecida "linha de cor" (color line), por outro lado não tinham "o calor humano" atribuído ao povo brasileiro:

4 "His idea is that Inter-American relations can be fostered by a mutual exchange of knowledge about the literature of the two Americas - not literature in the "literary" sense but books to be read for amusement (...) What Mr. Verissimo has in mind is entirely apart from the complimentary kind of literary interchange. His idea is that understanding of good and of bad is necessary, and that once such relations smack of propaganda, they fail. The tendency in Brazilian Literature already is toward the United States, he points out."

5 Todas as traduções de citação, neste artigo, são de minha autoria.

6 Waldo Frank fazia parte de um grupo de intelectuais de grande influência no começo do século, que questionava o materialismo cultural norteamericano e via no misto de natureza e espiritualidade das culturas dos países ao sul a humanidade que faltava aos Estados Unidos. Os Estados Unidos eram vistos, pelos membros desse grupo, como a parte masculina das Américas, e os povos latinos, a parte feminina; partes essas que deveriam se unir e não dominar uma à outra. (Tota, 2000:34-35).

TradTerm, 15, 2009, p. 59-78 
É nesse contexto que Érico Veríssimo chega aos Estados Unidos e seu objetivo é mostrar que o Brasil pode contribuir no proposto diálogo pan-americano, equilibrando o materialismo ianque com o "caráter mais humano" do brasileiro. (Machado, 2004:1)

Érico Veríssimo, que apenas completara o segundo grau no Brasil, permaneceu por alguns anos nos Estados Unidos, proferindo palestras nas universidades americanas e, em 1944, foi convidado a dar um curso na Universidade de Berkeley, na Califórnia (Machado, 2004). É que a editora MacMillan começou a publicar as traduções das obras de Veríssimo em 1943, com o lançamento de Crossroads (Caminhos Cruzados), seu único livro publicado ali durante o período da Segunda Guerra. E continuou a publicá-lo até 1965, sendo His Excellence, The Ambassador (Sua Excelência, o Embaixador) o último título de Veríssimo lançado nos Estados Unidos.

Em artigo publicado no jornal Los Angeles Times de 14 de novembro de 1944, Veríssimo surge novamente, alertando agora para as diferenças morais e religiosas entre as duas culturas (a principal questão levantada era o divórcio, aceito nos Estados Unidos, mas ainda mal visto no Brasil, onde a religião oficial sempre foi o catolicismo). Comentava sobre as críticas dos brasileiros ao materialismo, à falta de religiosidade e ao imperialismo norte-americano.

Em 4 de fevereiro de 1945 o The New York Times anunciava o lançamento da obra do autor gaúcho: Brazilian Literature: An Outline. O texto, produzido em idioma inglês, trazia uma bem humorada introdução à história da literatura brasileira. A crítica do The New York Times concluia:

Este livro é essencial para todos os interessados no desenvolvimento de uma solidariedade panamericana genuina. Ele tem a vantagem de ter sido escrito por um dos mais talentosos e populares escritores brasileiros. Nosso Departamento de Estado deveria ser encorajado a fazer um convite permanente a Érico Veríssimo para lecionar e dar palestras aqui. Com sua compreensão dos problemas em ambos os países, ele seria um dinâmico e muito simpá-

TRadTerm, 15, 2009, p. 59-78 
tico embaixador da boa-vontade. ${ }^{7}$ (The New York Times, 4 de fevereiro de 1945)

Com o passar dos anos, o autor já apresentava certo descontentamento com a imagem "holiwoodiana" do Brasil ${ }^{8}$ e buscava mostrar aos americanos a razão de algumas divergências culturais entre os povos. Suas opiniões foram veiculadas através destes ${ }^{9} \mathrm{e}$ de outros artigos dos jornais Los Angeles Times e The New York Times. Mas o mais importante é ver como o autor assumiu o papel de mediador, se tornando mesmo esse "embaixador" vinculado à atividade literária.

Durante o período da guerra, a questão racial também era marcadamente importante. Na Europa, Hitler impunha o arianismo e o genocídio de negros e judeus. Nas Américas, enquanto o Brasil era visto como o exótico "cadinho das raças" (melting pot para os norte-americanos), os Estados Unidos ainda enfrentavam os problemas de segregação racial criados desde a Guerra Civil ${ }^{10}$.

Foi então que começou a destacar-se o sociólogo brasileiro Gilberto Freyre. O pernambucano fora discípulo, nos Estados Unidos, de

7 'This book is a 'must' for all who are interested in the development of genuine Pan American solidarity. It has the advantage of having been written by one of the most talented and popular of Brazilian writers. Our State Department should be urged to extend a permanent invitation to Erico Veríssimo to teach and lecture here. With his friendly understanding of the problems in both countries, he would be a dynamic and muito simpatico ambassador of good-will."

8 "O Brasil que vocês conhecem é um Brasil falsificado, feito em Hollywood, que em geral nos apresenta ou como um país de opereta, em que homenzinhos que vestem fraque, usam cavanhaque e gesticulam como doidos beijam na rua e em plena face outros homúnculos igualmente grotescos; ou então com os recursos do tecnicolor nos mostram como uma terra de mirabolantes maravilhas. Não somos nem ridículos nem sublimes. Na minha terra, como aqui, há de tudo." (palestra de Veríssimo na Califórnia - apud Machado, 2004: 3).

9 Los Angeles Times, de 18 de abril de 1941e de 14 de novembro de 1944; The new York Times, de 6 de fevereiro de 1944 e de 4 de fevereiro de 1945, entre outros.

10 The New York Times de 26 de agosto de 1945.

TradTerm, 15, 2009, p. 59-78 
Franz Boas, que dedicara grande parte de suas reflexões e pesquisas à resolução de problemas sociais, como o racismo e a suposta superioridade cultural de certos povos. Em 1933 Freyre lançara Casa Grande e Senzala, onde invertia o caráter pejorativo até então atribuído à mestiçagem e valorizava as culturas de povos africanos. As comparações de Freyre também focavam o Brasil e os Estados Unidos, colocando o Brasil numa posição privilegiada quanto à questão do racismo. Materialismo e raça se tornariam, assim, os principais pontos de discussão para a comparação entre as Américas. Ea questão diplomática, a mola propulsora para a literatura traduzida.

No ano de 1942, enquanto vários intelectuais brasileiros ainda chegavam aos Estados Unidos, editoras universitárias e particulares usavam os incentivos financeiros do Departamento de Estado Americano para fechar contratos de tradução com autores brasileiros.

Um dos primeiros livros traduzidos, publicado em decorrência dessas contratações, foi Os Sertões, de Euclides da Cunha, provavelmente por representar um grande ensaio sobre nossa história. Mas o tempo de realização das traduções no começo da década de 1940 era longo e isso fez com que o lançamento da obra acontecesse apenas em 1944. A critica, publicada no The New York Times em 6 de fevereiro daquele ano, é do próprio Veríssimo. Ele explicava que tanto governantes quanto escritores brasileiros não mais tentavam resolver os problemas do sertão com expedições armadas, mas sim com compreensão, criação de escolas, higiene, leis trabalhistas e auxílio social. Veríssimo tentava convencer o público americano de que o povo brasileiro era antitotalitário e contra a violência:

A tônica de sua vida é uma mistura deliciosa de malícia e amabilidade, combinadas com sentimentalismo e um toque boêmio. Eles têm um senso de humor maravilhoso e não se interessam muito por uma civilização expressa em termos de dinheiro e progresso mecânico. ${ }^{11}$ (The New York Times de 6 de fevereiro de 1942)

11 "The keynote of their life is a delicious mixture of malice and kindness, blended with sentimentality and with a Bohemian touch. They have a wonderful sense of humor and don't care very much for a civilization expressed in terms of money and mechanical progress."

TradTerm, 15, 2009, p. 59-78 
Veríssimo finalizava dizendo que, quando vencidos os problemas de pobreza, analfabetismo e saúde, o Brasil concretizaria as esperanças de Stefan Zweig, cumprindo seu destino de país do futu$\mathrm{ro}^{12}$. O autor gaúcho usava sua habilidade de escritor para inverter o caráter determinista transmitido pela obra de Da Cunha, além de deixar claro que as correntes mais contemporâneas à época ${ }^{13}$ já discordavam do "exagero" de Da Cunha quanto à questão das raças.

\section{Traduções no Pós-Guerra: $O$ apoio de Alfred Knopf e dos criticos do The New York Times}

O fato de as traduções de obras brasileiras serem publicadas 3 a 4 anos após sua contratação pode ter sido um dos impedimentos para uma melhor recepção das obras no continente norte-americano.

Em 1944 o Office of the Coordinator of Inter-American Affairs foi transformado em Office of Inter-American Affairs. Getúlio Vargas foi deposto no Brasil em 1945 e Franklin Roosevelt morreu nesse mesmo ano. Em 1946 a Segunda Guerra já tinha terminado e as atenções governamentais, editoriais e até mesmo do público leitor já se desviavam novamente para a Europa. O Office of InterAmerican Affairs foi extinto em maio de 1946 pelo presidente Harry Truman. Com o início da Guerra Fria, essa situação somente se acentuaria. As atenções se desviavam para a Europa e para a Ásia, com destaque para a China e a Coréia (Tota, 2000:190).

No campo das traduções literárias ainda se sentiam os efeitos da política de Roosevelt. Entre 1945 e 1946 foram publicadas as traduções de Terras do Sem Fim, de Jorge Amado, Angústia, de Graciliano Ramos, e Casa Grande e Senzala, de Freyre. Brazil: an Interpretation, também lançado nessa época, foi uma obra escrita

12 Stefan Zweig escreveu Brasil, pais do futuro, publicado em 1941. Cf. Herbertz, Adelaide Stoos (2007) "Os leitores e as leituras da obra de Stefan Zewig no Brasil”. Fênix, Revista de História e Estudos Culturais. Mai/Jun/Jul.

13 Veríssimo certamente se referia às correntes de defesa da mestiçagem, cujo maior defensor foi o próprio Freyre.

TRADTERM, 15, 2009, p. 59-78 
diretamente no idioma inglês por Freyre. Todas essas publicações foram realizadas pela Alfred A. Knopf Publishers.

Alfred Knopf já vinha se destacando nos Estados Unidos por trabalhar com literatura traduzida. Quando o mercado editorial europeu se fechou às nações americanas no começo da Segunda Guerra, Knopf aproveitou os incentivos do Departamento de Estado Americano para seu projeto de tradução na América Latina. Sua esposa e sócia, Blanche Knopf, viajou pela região, buscando obras que retratassem os países ao sul. Fechou, então, um contrato para traduzir o ensaio de Freyre e os romances de caráter político já citados. O jornal nova-iorquino testemunhou todos esses lançamentos ${ }^{14}$.

Mostrando a continuada preocupação com as relações diplomáticas, o The New York Times trazia os seguintes comentários sobre a publicação de Brazil: an Interpretation:

Que lado tomarão os países ao nosso sul no mundo pósguerra? Eles ficarão satisfeitos em seguir o norte industrial e imitar seu progresso material? Ou eles, fiéis ao seu passado genial, apontarão um novo caminho em termos de Humanidades ou do que chamam agora as ciências sociais? Gilberto Freyre, um brilhante sociólogo do Brasil, prevê para seu país uma resposta neste livro, feito a partir de palestras que ele proferiu na Universidade de Indiana no inverno passado. ${ }^{15}$ (Adams, Mildred. The New York Times de 26 de agosto de 1945)

Como visto anteriormente, a questão das raças se tornara crucial à nação americana. No mesmo artigo citado acima, Mildred

14 The New York Times de 26 de agosto de 1945, 31 de março de 1946, e de 6 de outubro de 1946.

15 What part will the countries to the south of us take in the post-war world? Will they be content to follow the industrial north and imitate its material progress? Or will they, true to their past genius, point out new paths in terms of humanities or what are now called the social sciences? Gilberto Freyre, brilliant young sociologist from Brazil, foreshadows for his country a possible answer in this book, made up of lectures, which he delivered at the Indiana University last winter.

TRADTERM, 15, 2009, p. 59-78 
Adams declara que, segundo Freyre, no Brasil a mestiçagem não era mais vista como mácula; o preconceito existia mais como resultado da consciência de classes do que de raça ou $\operatorname{cor}^{16}$. Mais ainda: para Freyre, o Brasil era um país que tinha orgulho de seus elementos de base ameríndia, judaica e africana, e onde os jovens brasileiros consideravam um dever opor-se a qualquer tipo de discriminação racial. Sem deixar de questionar o caráter utópico das afirmativas de Freyre, Mildred Adams afirmava que Casa Grande e Senzala tinha sido aclamada como uma contribuição de valor para o aprendizado mundial, anunciando sua breve publicação nos Estados Unidos.

Grande destaque também foi dado à publicação de Casa Grande e Senzala, "um presente dos deuses para quem [gostaria de] entender a terra e o povo brasileiro" 17 (Herring, Hubert. New York Times de 6 de outubro de 1946). A tônica da obra não se afasta daquela de Brazil: an Interpretation. A crítica do jornal nova-iorquino dava novo destaque à obra de Freyre, sem deixar de agradecer ao tradutor Samuel Putnam (especialmente pelo bom trabalho) e ao editor Alfred Knopf por trazerem diversas obras latino-americanas para os Estados Unidos. É possivel que a inclusão quase estratégi$\mathrm{ca}^{18}$ da comunidade judaica na obra de Freyre também tivesse chamado a atenção do editor e do tradutor após o extermínio causado por Hitler. Mais tarde Knopf viria a se tornar amigo e "compadre" 19 de Freyre e daria grande apoio a sua obra (Rostagnor, 1997:42). Alheio às mudanças nas relações diplomáticas entre os

16 As ideias de Freyre foram combatidas por diversos intelectuais em vários estudos, entre eles: Bastide, Roger e Fernandes, Florestan (1955) Negros e brancos em São Paulo. São Paulo: Anhembi, e HASENBALG, Carlos A. (1979) Discriminação e desigualdades raciais no Brasil. Rio de Janeiro, Graal.

17 "a gift of the gods to all who would [sic] understand the Brazilian land and people ".

18 Já que acrescentava mais um povo ao "cadinho das raças", além dos que já formavam o "mito das três raças": aquele que mais havia sofrido com as perseguições nazistas.

19 Knopf batizou a neta de Freyre.

TRADTERM, 15, 2009, p. 59-78 
dois países, Knopf transformaria a tradução de obras brasileiras em seu "pet project"20.

Putnam e Knopf também foram responsáveis pela publicação, algum tempo depois, de uma nova obra sobre nossa literatura. Marvelous Journey: Four Centuries of Brazilian Writing ${ }^{21}$, de Samuel Putnam, era uma publicação que também reproduziria a linha ideológica da Boa Vizinhança, como mostrava o jornal nova-iorquino, em 25 de julho de 1948:

Neste ponto do nosso relacionamento com a América Latina, quando a histeria do período de guerra parece tender a ser sucedida por um retorno à nossa prévia indiferença, livros que nos ajudam em direção a uma posição equilibrada são exatamente aquilo de que precisamos. E em lugar algum é a necessidade maior do que no campo de nossa compreensão sobre o Brasil, o melhor amigo que nós temos na América do Sul e uma nação destinada a um grande futuro, se a raça humana sobreviver a sua crise atual. ${ }^{22}$ (The New York Times de 25 de julho de 1948)

O reconhecimento dado a Alfred A. Knopf por publicações de obras brasileiras não aconteceu, no entanto, apenas dentro dos Estados Unidos. Aqui no Brasil, Blanche Knopf foi homenageada pelo governo brasileiro. Em 1950 ela foi condecorada com o título de "Cavaleiro(a) da Ordem do Cruzeiro do Sul", por seu empenho em divulgar nossa literatura nos Estados Unidos ${ }^{23}$. Anos mais tar-

20 Projeto de estimação.

21 Jornada Maravilhosa: Quatro Séculos da Escrita Brasileira.

22 "At this point in our relationship with Latin America, when the hysteria of the war period seems likely to be succeeded by a return to our previous indifference, books which will helps us toward a balanced attitude are exactly what we need. And nowhere is the need greater than in field of our understanding of Brazil, the best friend we have in South America and a nation destined for a great future, if the human race survives its present crisis."

23 Fato anunciado na edição do The New York Times de 3 de novembro de 1950.

TRADTERM, 15, 2009, p. 59-78 
de, Alfred e Blanche seriam novamente homenageados com insignias da Ordem do Cruzeiro do Sul ${ }^{24}$.

Nesse contexto ainda, o que se confirmava era o papel do The New York Times não apenas como veículo de informações, mas como importante instrumento de formação de opinião, apoiando as ideias de intercâmbio cultural originadas no governo Roosevelt. O The New York Times manteve, a partir da década de 1950, uma coluna chamada "Literary Letter From Brazil", que contou com a constante contribuição do escritor, crítico e também jornalista Antônio Callado. Ex-correspondente da BBC durante a Segunda Guerra e tendo trabalhado no Serviço Brasileiro da Radio-Diffusion Française, em Paris, Callado não era apenas politizado, mas também muito ativo dentro e fora do Brasil. Viria a escrever Quarup em 1967, que seria também publicado em tradução inglesa por Knopf em 1970. Na década de 1950, no entanto, Callado fazia a critica das obras brasileiras no The New York Times tecendo especiais elogios ao "romance do nordeste". Não coincidentemente, em 1956 a editora da Universidade da Califórnia, em Berkeley, publicou a obra Brazil's New Novel: Four North-eastern Masters ${ }^{25}$, do professor Fred P. Ellison, que era, na verdade, um ensaio crítico sobre as obras de Jorge Amado, José Lins do Rego, Raquel de Queiroz e Graciliano Ramos.

Já Knopf publicou uma reedição da tradução de Casa Grande e Senzala, também em 1956. O fato era, de certo, um reflexo do interesse da UNESCO pela obra de Freyre e da execução de um projeto de pesquisas sobre a relação das raças no Brasil alguns anos antes ${ }^{26}$. Voltamos a encontrar uma outra publicação brasi-

24 Relatórios das atividades desenvolvidas pela Embaixada do Brasil em Washington durante a gestão de Juracy Magalhães, que cobriu o período de junho de 1964 a outubro de 1965. Washington. Disponivel no Centro de Pesquisa e Documentação de História Contemporânea do Brasil (CPDOC) da Faculdade Getúlio Vargas - SP. Classificação JM pi BR-Emb. EUA 1964.12.00. Centro de Pesquisa e Documentação de História Contemporânea do Brasil (CPDOC) da Faculdade Getúlio Vargas - SP. O Novo Romance Brasileiro: Quatro Mestres Nordestinos.

26 MAIO, M. C. (1999) "O Projeto UNESCO e a Agenda das Ciências Sociais no Brasil dos Anos 40 e 50”. Revista Brasileira de Ciências Sociais. São Paulo, vol. 14, $\mathrm{n}^{\circ} 41$, pp. 141-158.

TradTerm, 15, 2009, p. 59-78 
leira de Knopf apenas em 1959, com o lançamento de New World in the Tropics. A obra era uma nova versão de Brazil: an Interpretation, também de Freyre, que agora se apresentava em universidades americanas e europeias com palestras sobre a "democracia racial" brasileira.

\section{0 ressentimento no periodo da Guerra Fria}

O jornal nova-iorquino também foi fonte de narrativas sobre as instabilidades diplomáticas entre o Brasil e os Estados Unidos no período da Guerra Fria.

Em $1^{\circ}$ de abril de 1951, o The New York Times publicava um artigo com a manchete: "Brazil is Smarting from U.S. Neglect"27. Como subtitulo lia-se: "The Best Friend of Yankees Among Latins Has Many Grievances, Some of Them Justified"28. O artigo relatava que a nação, cuja amizade tinha sido subestimada e cujo papel na Segunda Guerra tinha sido esquecido, agora reclamava da falta de apreciação. O Brasil se ressentia por sua exclusão do Plano Marshall, pelas perdas causadas com a inflação norte-americana do pós-guerra e pela falta de generosidade nos empréstimos. Não ficava de fora o ressentimento sobre um grande empréstimo feito à Argentina que, ao contrário do Brasil, mantinha uma política externa muito mais hostil para com os Estados Unidos. Além disso, os grandes empresários brasileiros alegavam que os Estados Unidos queriam dominar a economia brasileira, mantendo-a basicamente agrícola. O jornal americano apresentava tais críticas brasileiras como "positivas", quando comparadas à ação da intelligentsia comunista e dos nacionalistas "antiianque", que contribuiam para o abalo na "amizade entre os vizinhos". Mas o artigo contrapunha que várias queixas brasileiras eram injustificadas, uma vez que os empréstimos do Import-Export Bank para o Brasil tinham sido maiores do que os concedidos a qualquer outro país

O Brasil está ressentido com o descaso dos Estados Unidos.

28 O Melhor Amigo dos Ianques entre os Latinos Têm Muitas Queixas, Algumas delas Justificadas.

TRADTERM, 15, 2009, p. 59-78 
latino-americano. Dizia, ainda, não ser verdade que os Estados Unidos queriam dominar a economia brasileira, e acrescentava que acabara de ser criada a Joint Brazilian-American Economic Development Commission ${ }^{29}$, para solucionar muitas dificuldades econômicas. O argumento mais curioso era, no entanto, o de que o Serviço de Informação dos Estados Unidos instalado no Brasil era o maior da América Latina e um dos maiores do mundo, além de ser um dos mais impressionantes e bem sucedidos, o que não indicava negligência ${ }^{30}$.

A iniciativa servia como exemplo de que o conhecimento sobre os Estados Unidos era trazido ao Brasil, ao passo que o inverso não acontecia. O artigo sugeria, contudo, no que parecia uma tentativa derradeira de "acalmar os ânimos", que tais ressentimentos ou reclamações eram querelas entre dois bons amigos, nada comparado ao antagonismo existente entre os Estados Unidos e a Argentina, nem com a campanha antiamericana de Juan D. Perón. Não ficava esquecido o fato de Getúlio Vargas, o ex-ditador populista que "adorava aplausos", estar subindo novamente ao poder num momento delicado de uma democracia ainda nova. Getúlio Vargas, eleito democraticamente e com grande apoio popular, era apresentado como alguém que podia agora fazer o que quisesse em nome da democracia, mas que não tinha mais motivos para se voltar para os antigos métodos totalitários. Era, pois, um "ator soberbo", que podia agora interpretar o papel de um democrata. Segundo o artigo, o grande perigo vinha do comunismo, tornado ilegal no Brasil em 1947, mas ainda forte graças à terrivel pobreza e ao prestígio do líder comunista Luis Carlos Prestes. A conclusão era de que, apesar de o Brasil não representar grandes ameaças, isso não significava que o mais poderoso e melhor amigo da América Latina podia ser ignorado de forma segura.

29 Comissão Conjunta Brasileira-Americana para o Desenvolvimento Econômico.

30 A obra de Pedro Tota (2000) descreve a implantação desse Sistema de Informação no Brasil, vinculado ao OCIAA, como forma de expandir o processo de "americanização" do Brasil.

TRadTerm, 15, 2009, p. 59-78 


\section{A Revolução Cubana e as novas traduções de Knopf}

Todo o contexto sócio-histórico descrito anteriormente serviu como preparação de terreno para o que viria a acontecer na década de 1960. Com a Revolução Cubana, as atenções do governo dos Estados Unidos se voltaram novamente para o continente americano. Mas diferentemente do que ocorrera anteriormente, a questão central do conflito agora se instaurara na América Latina, e o perigo da expansão comunista no continente era iminente. Kennedy retomaria, em grande parte, a filosofia de "Boa Vizinhança" de Roosevelt, agora sob a roupagem da "Aliança para o Progresso". Segundo o The New York Times de 20 de maio de 1961, o governo de Jânio Quadros mostrava uma independência desconcertante quanto aos assuntos internacionais. O ministro das Relações Internacionais do Brasil emitira uma declaração defendendo o direito de Cuba à autodeterminação e opondo-se a qualquer intervenção estrangeira. O jornal informava que o presidente Kennedy sabiamente resistia à tentação de associar a ajuda financeira ao Brasil às concessões ou interferências políticas.

Enquanto isso, os criticos literários do The New York Times anunciavam uma nova geração de autores que substituiriam os antigos escritores da década de $1940^{31}$. Entre eles figuravam Jorge Amado e Guimarães Rosa. Todavia, quem levaria a literatura brasileira traduzida à lista de bestsellers do The New York Times não seria o governo ou as universidades americanas, mas sim o próprio Alfred Knopf, com a publicação de Gabriela, Clove and Cinnamon (Gabriela, Cravo e Canela), de Jorge Amado.

Em 1951, o escritor Jorge Amado, ainda envolvido com a ideologia comunista, recebera o Prêmio Stalin da Paz, fato anunciado no The New York Times de 22 de dezembro daquele ano. O que naquele momento parecia impossivel tornar-se-ia realidade aproximadamente dez anos mais tarde, numa reviravolta que só não foi mais surpreendente porque foi, antes de qualquer coisa, uma demonstração do dinamismo da história e da adaptabilidade da literatura traduzida: um romance de Jorge Amado se tornaria um sucesso comercial norte-americano.

31 The New York Times de $1^{\circ}$ de dezembro de 1961.

TradTerm, 15, 2009, p. 59-78 
Apenas 5 anos antes da publicação de Gabriela, em 1962, o escritor baiano tinha se desligado do comunismo, decepcionado com os rumos do Partido e do stalinismo. Apesar disso, o caráter político e de contestação não deixara de existir na obra amadiana. Amplamente conhecida na Europa, a obra de Amado já era um fenômeno de tradução: o romance Gabriela tinha sido traduzido para 14 idiomas. O público americano não era indiferente ao seu sucesso internacional, mas o romance precisava ser assimilado de forma própria, como mostrava o jornal nova-iorquino:

Já um bestseller no Brasil, ele está agendado para ser publicado em mais de uma dúzia de países. Se suas outras traduções forem tão habilmente fluentes, cheias de vida e naturais como a tradução inglesa de James L. Taylor e William Grossman, a heroína "cor de canela" do Sr. Amado tem uma chance se tornar tão internacionalmente famosa como aquelas outras beldades latinas Gina Lollobrigida e Sophia Loren. ${ }^{32}$ (The new York Times de 12 de setembro de 1962)

William Grossman tinha sido convidado a "melhorar" a primeira tradução feita por James L. Taylor, que desagradara a Knopf. Mas o resultado final também não agradou muito ao crítico do Los Angeles Times, que publicou em 28 de outubro de 1962:

Compreensivelmente dificil é a tarefa de traduzir a qualidade poética da prosa de Jorge Amado. A inadequação de tom de várias traduções, a transposição de um número de expressões para um nivel cultural mais alto ou mais baixo do que o usado pela personagem em questão, e algumas omissões do texto original, embora deploráveis, não são sufici-

32 "Already a best seller in Brazil, it ["Gabriela"] is scheduled to be published in more than a dozen countries. If its other translations are as expertly smooth, racy and natural as the English translation by James L. Taylor and William Grossman, Mr. Amado's "cinnamon-colored" heroine has a chance of becoming as internationally famous as those other Latin charmers, Gina Lollobrigida and Sophia Loren.”

TradTerm, 15, 2009, p. 59-78 
entes para arruinar o estilo caracteristicamente fluente e refrescantemente popular do autor para leitor falante do inglês. ${ }^{33}$ (Los Angeles Times, de 28 de outubro de 1962)

Décadas mais tarde os desvios evidenciados pelo Los Angeles Times também levariam a críticas no Brasil, de que a tradução teria priorizado o erotismo da obra em detrimento das questões político-sociais do romance ${ }^{34}$. De qualquer forma, o que se viu em 1962 foi Gabriela chegar aos Estados Unidos como uma "Impulsive Child of Nature ${ }^{35 "}$, a mulata brasileira que, após conquistar o mundo, também conquistaria o mercado leitor americano. "The café au lait Gabriela is as sweet and spicy as the title of this best selling Brazilian novel implies ${ }^{36 "}$, dizia o jornal norte-americano. E a forma como o caráter político de Jorge Amado foi tratado na época pode ser visualizada através da crítica de Juan de Onís, filho da tradutora Harriet de Onís, também no The New York Times de 16 de setembro de 1962:

"Gabriela" representa, sem dúvida, a liberação artística do Senhor Amado de um longo período de compromisso ideológico com a ortodoxia comunista. Ele não teve de fazer uma declaração pública a respeito de sua presente

33 "Understandably difficult is the task of translating the poetical quality of Jorge Amado's prose. The tonal inadequacy of several translations, the rendering of a number of expressions at a higher or lower cultural level than that used by the character in question, and some complete omissions from the original text, although deplorable, are not sufficient to appreciably mar the author's characteristically smooth and refreshingly popular style for the English speaking reader."

34 Cf. CORREIA, Adilson da Silva (2003) "Gabriela na malha da tradução domesticadora dos anos 60". Congresso Nacional de Estudos Filológicos e Lingüísticos. Rio de Janeiro, 7.

35 "Uma filha impulsiva da natureza" (The New York Times de 12 de setembro de 1862).

36 A morena ["café au lait" vem do francês e significa "café com leite", referindo-se à cor da mulata/ Gabriela é tão doce e picante quanto o título deste romance brasileiro campeão de vendas sugere. (Los Angeles Times de 28 de outubro de 1962).

TRADTERM, 15, 2009, p. 59-78 
visão para mostrar que sua integridade artística prevaleceu sobre a linha intelectual partidária. Ele ficou chocado com o derramamento de sangue na Hungria e criticou publicamente o manejo soviético do caso Pasternak e, nessas recentes reações, ele está muito próximo a intelectuais europeus, tais como Jean Paul Sartre, de quem é amigo pessoal. O Senhor Amado continua a seguir de perto o desenvolvimento político do Brasil, mas está completamente convencido de que doutrinas rígidas extraídas da experiência russa são agora de pouco valor para o Brasil, onde ele acredita que as mudanças democráticas e pacíficas ainda são possiveis. ${ }^{37}$

A literatura de Jorge Amado adentrou, assim, o sistema literário americano da única forma possivel durante a Guerra Fria: como um exemplo de "rejeição" à doutrina Russa. E em poucas semanas entraria para a lista de bestsellers do The New York Times, para lá permanecer por quase um ano.

\section{Conclusões}

O que verificamos no presente artigo é a forma como redes de atores e grupos de influência e resistência interagiram através de diferentes projetos, em constante diálogo e negociação. Todo esse processo foi documentado em jornais como o The New York Times,

37 “'Gabriela' represents undoubtedly the artistic liberation of Senhor Amado from a long period of ideological commitment to Communist orthodoxy. He has not had to make a public profession of his present views to show that his artistic integrity has prevailed over the intellectual "Party line". He was shocked by the Hungarian bloodbath and publicly criticized the Soviet handling of the Pasternak case and, in these reactions, he is very close to Europeans intellectuals, such as Jean Paul Sartre, with whom he is personally friends with. Senhor Amado continues to follow Brazil's political development closely, but he is fully convinced that rigid doctrines drawn from the experience of the Russian revolution are now of little value for Brazil, where he believes democratic, peaceful social changes are still possible."

TRADTERM, 15, 2009, p. 59-78 
criando para o leitor norte-americano narrativas sobre as principais questões em debate entre a Segunda Guerra Mundial e a Guerra Fria. A tradução literária foi tida por muitos como um importante instrumento de assimilação da cultura das nações vizinhas. Mas o que se iniciou com uma agenda maior, de manutenção de poder durante um período de guerra, se desdobrou em várias subagendas. $\mathrm{E}$ foi o confronto entre as forças dos diferentes grupos que contribuiu, momentaneamente, para o sucesso ou o insucesso comercial das traduções literárias de obras brasileiras nos Estados Unidos.

Os fatos aqui descritos aconteceram há mais de cinquenta anos, sob circunstâncias históricas que já se modificaram muito. Eles fazem parte, todavia, de um mosaico que nos possibilita compreender um pouco da história e das forças que movem a atividade de tradução.

\section{Referências Bibliográficas:}

ANDERSON, Benedict (1991) Imagined Communities: Reflections on the Origin and Spread of Nationalism. London and New York: Verso, Revised Edition.

COHN, Deborah (2003) Retracing The Lost Steps: The Cuban Revolution, the Cold War, and Publishing Alejo Carpentier in the U.S. The New Centennial Review, 3.1.

CORREIA, Adilson da Silva (2003) Gabriela na malha da tradução domesticadora dos anos 60. Anais do Congresso Nacional de Estudos Filológicos e Lingüísticos, Rio de Janeiro, 7.

MACHADO, Ronaldo (2004) Entre o centro e a periferia: Érico Veríssimo nos Estados Unidos, 1944. Anais do VI Encontro do "BrasilianistenGruppe in der ADLAF”. Berlim.

MAIO, M. C. (1999) O Projeto UNESCO e a Agenda das Ciências Sociais no Brasil dos Anos 40 e 50. Revista Brasileira de Ciências Sociais. São Paulo, vol. 14, n . 41, pp. 141-158.

ROSTAGNO, Irene (1997) Searching for Recognition: the promotion of Latin American Literature in the United States. London: Greenwood Press.

TOTA, Pedro (2000) O Imperialismo Sedutor: a americanização do Brasil na época da Segunda Guerra. São Paulo: Companhia das Letras.

TRADTERM, 15, 2009, p. 59-78 